EPJ Web of Conferences 33, 05002 (2012)

DOI: $10.1051 /$ epjconf/20123305002

(C) Owned by the authors, published by EDP Sciences, 2012

\title{
A Low Carbon City Action Plan for one of China's Low Carbon Pilot Cities
}

\author{
D. Jakutyte-Walangitang ${ }^{1, a}$, J. Page ${ }^{2, b}$ \\ ${ }^{1}$ AIT, Energy Department, Giefinggasse 2, 1210 Vienna \\ ${ }^{2}$ AIT, Energy Department, Giefinggasse 2, 1210 Vienna
}

\begin{abstract}
In Chinese cities urbanization, industrialization and a changing life style of the population are driving growing energy consumption in buildings, industries and transportation and an increase in $\mathrm{CO}_{2}$ emissions. Facing these challenges, the National Development and Reform Commission has recognised an urgent need for transformation and designated 8 Cities and 5 Provinces in China to pioneer the planning and implementation of concrete low carbon measures, aiming to decrease the $\mathrm{CO}_{2}$ intensity of the economic development, to increase the energy efficiency of urban systems and to improve the quality of life in growing urban regions. In this context, a Sino-Austrian cooperation has been initiated between the Development and Reform Commission of Nanchang, one of the 8 selected Low Carbon Pilot Cities, and the Austrian Institute of Technology to develop a comprehensive set of Low Carbon City Measures and a Low Carbon City Action Plan, proposing specific technological and non-technological measures and concrete actions, capable of introducing important impulses targeting the increase of energy efficiency and the reduction of $\mathrm{CO}_{2}$ emissions in Nanchang. A team of experts has developed an integrated Low Carbon City Action Plan, including sectors such as buildings, energy supply and consumption, industries, transportation, agriculture and urban planning.
\end{abstract}

\section{Introduction}

In the post-reform China cities have served as catalysts for the unprecedented speed of economic development. Alongside industrial progression, real estate market has been established [1,6], forming an essential element in the fast paced urban transformation. Since 1978 Chinese National, Provincial and Local Governments have utilized the processes of land accumulation and development fostering rural-urban migration and economic growth. According to the "2008 China's Urbanization Report" compiled and edited by the China Association of Mayors [2] China's urbanization level had reached 45.68 per cent in the year 2008 [

Fig. 1] compared to 20 percent in 1980. In 2008, the number of cities with a population between 1 and 2 million had reached 35, compared to 13 in 1978 and the number of cities with population exceeding 2 million - 23 [3]. While these statistics capture the magnitude of urbanization and expansion, they say very little about the qualitative characteristics and features of such development. Inevitably the question arises, what are the consequences of such transformation and what type of adjustments are necessary to impede negative effects of physical and economic growth on the environment. Within this context, a critical role has to be assigned to the urban energy systems. Most current statistical figures [4-5] confirm the ongoing, energy intensive path of urban development

\footnotetext{
a e-mail : daiva.walangitang@ait.ac.at

b e-mail : jessen.page@ait.ac.at
}

This is an Open Access article distributed under the terms of the Creative Commons Attribution License 2.0, which permits unrestricted use, distribution, and reproduction in any medium, provided the original work is properly cited. 
taking place in China. An understanding of the significance of the energy efficiency topic has gained momentum in recent years [7] and the first attempts of governmental interference have started to take a more constructive and defined shape.

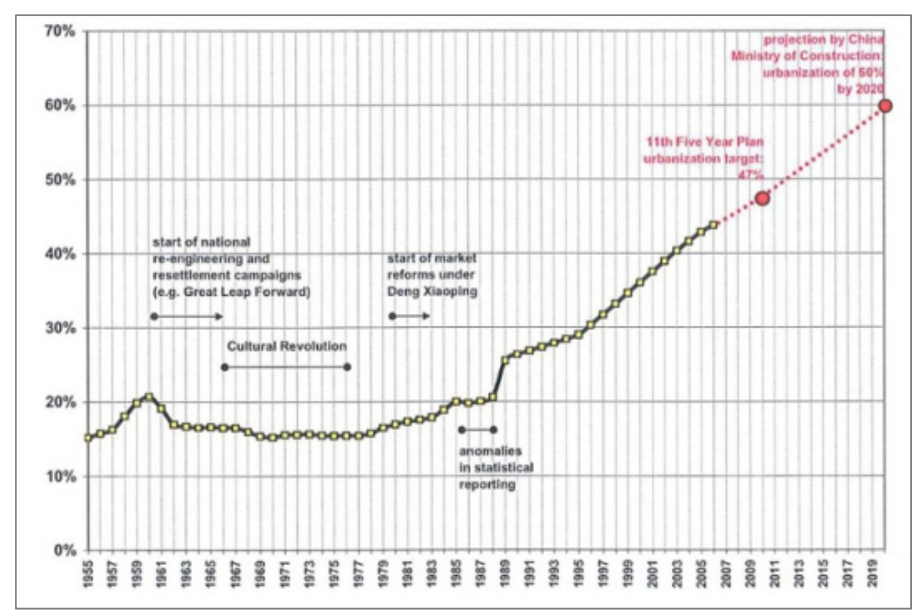

Fig. 1 China's Urbanisation, 1955-2020

Source: Department of Foreign Affairs and International Trade, Canada (2008), Emerging Trends in China

Formerly marginal role of energy security in a growing economy has become a paramount issue in the National 12th Five Year Plan, which defines clear energy related targets for the time period 2011-2015, addressing environmental challenges and confronting substantial issues in the fields of urban energy efficiency and energy supply [7]. Closely tied to the energy topic are the prospects of reduction of $\mathrm{CO}_{2}$ emissions, which have taken a central position among the aims in the 12th 5 Year Plan.

\section{Pioneering the transformation? Nanchang - one of the Low Carbon Pilot Cities in China}

Recognizing the threats posed by the rapidly growing demand for energy and facing potential energy shortage, various levels of Chinese government have expressed a clear determination to implement energy and climate change goals:

- A 16 per cent reduction in energy intensity (energy consumption per unit of GDP)

- Increasing non-fossil energy to 11.4 percent of total energy production

- A 17 per cent reduction in carbon intensity (carbon emissions per unit of GDP) [7]

To pioneer the implementation of the $12^{\text {th }} 5$ Year Plan aims, 8 cities and 5 provinces have been designated and charged with the task to pursue the path of a low carbon transformation. Implementing the national policies on the local level, the governments of the piloting region are showing their commitment to take serious action to decrease energy intensity and $\mathrm{CO}_{2}$ emissions within their territorial units. One of the designated Low Carbon Pilot Cities is the city of Nanchang, the primary urban centre of the Jiangxi Province, located in the central region of China. Nanchang city caters for a metropolitan population of 4.9 million people, covering an area of $7402 \mathrm{~km}^{2}$ [8].

The current character of Nanchang exposes a lower degree of urbanization in comparison to the coastal cities, due to its location and the industrial typology [1]. However, the new special position of Nanchang as a Low Carbon Pilot City is drawing more attention into this region. In addition, a changing national strategy, focusing on diverting the development pressure from the coastal 


\section{$2^{\text {nd }}$ European Energy Conference}

metropoles towards less developed central regions, present Nanchang with a unique opportunity to transform its urban and industrial structures and to position the city on a higher level of competitiveness in Chinese urban hierarchy. Such situation introduces chances and challenges at multiple levels and at the same time. Nanchang's officials have embarked on the track of attracting foreign direct investment, encouraging urbanization and, simultaneously transforming patterns of urbanization and industrial structure towards a low carbon, energy efficient models of development [9-10]. This ambition contains, indeed, an opportunity to set up an energy efficient form of urban growth in Nanchang. To be successful, however, such development requires an integrated approach, motivating and involving all relevant stakeholders in the inspection process of existing barriers and disincentives in the field of energy supply on the one hand, and the end use energy efficiency on the other. The level of determination and the willingness of the local actors to interfere with the present structures and processes of development and to take corrective actions at all necessary levels will finally determine the rate of success of this undertaking.

\section{An interdisciplinary and participative process of Sino-Austrian cooperation}

In spring of 2011, the Development and Reform Commission of Nanchang has entrusted the Austrian Institute of Technology, Energy department with the task to develop a Low Carbon City Action Plan. This intense process of collaboration became a process of innovation itself, requiring such form of application of our European expertise, which would unfold solutions, compatible with local conditions of Nanchang. Inevitably, the Austrian and Chinese expert teams were confronted with different methods of working and communication, facing the challenge of understanding not only heterogenous transdisziplinary perspectives, specific to various fields of expertize, but also to get accustomed to varying working cultures, characteristic to Chinese and to Austrian work environments. One of the greatest challenges that the Austrian team of experts faced during this project was to maintain the scientific awareness that the Austrian and European best practice examples are bound to the European political, economic and urban context and might fail in Chinese context of development. Thus, a close, participative process of consultation with local experts in Nanchang and an integrated approach to development of a Low Carbon Action Plan became an obvious approach to solving this complex task.

\section{Approach and methodology}

\subsection{Application and integration of trans-disciplinary methods in analysis of urban energy system of Nanchang}

Careful scrutinizing of the status quo situation, including an elaborate analysis of the Key Performance Indicators (KPI) of the existing energy system in Nanchang formed the core of assessment process. A deliberate focus on taking an integrated, holistic approach for development of the Low Carbon Action Plan led to the selection of a variety of methods to be used for evaluation, given the high level of complexity of the task and a tight time budget of the project. As a result, a range of methods were selected and applied at the same time, using trans-disciplinary perspectives and aiming to generate the best possible, cumulative outcome.

In the first place, an extensive data collection and evaluation was performed. This method of evaluation allowed only a marginal assessment of energy performance profile and inventory of greenhouse gas (GHG) emissions in Nanchang, due to a large degree of fragmentation and inconsistency in provided data sources. As part of this process, a number of questionnaires was released to the expert team in Nanchang, requesting the inputs from local sources of information and integrating their expertise. 
The structure of questionaires included core elements of urban energy system of Nanchang, which have a high level of impact on the energy performance profile and the inventory of GHG emissions. Following components were included in evaluation:

- Demographics

- Urban Structure

- Buildings

- Energy supply network

- Transportation

- Industries

The described method of data assessment was completed by a decision support tool, dedicated to a specific type of calculations, integrating data and generating outputs in form of KPIs in the following three main areas:

- $\mathrm{CO}_{2}$ emissions, showing the quantity of emitted $\mathrm{CO}_{2}$, either as an absolute value in tons or in relative values in tons per capita or tons per unit of GDP,

- Renewable electricity production, exposing the share of electricity that is produced using renewable energy sources, compared to electricity produced using fossil fuel,

- Modal split, showing the use of different transportation modes within the city, in terms of distance travelled by passengers.

In addition to the evaluation of status quo urban energy profile of Nanchang based on statistics, a City Visioning Exercise and SWOT (Strengths, Weaknesses, Opportunities, and Threats) analysis were used during first joint Workshop in Nanchang, allowing Austrian team to gain important insights into the present, specific features of Nanchangs development, which cannot be disclosed in a purely statistical evaluation. This exercise ensured that the expertise and experience of local team was considered and integrated in the process of "filtering" of distinct local conditions, and priorities. More importantly, this participatory approach allowed Austrian team to understand most pressing local issues and desired routes of urban development, serving as a valuable source of information.

An equally important element of analysis was formed by a qualitative assessment of Nanchang's spatial structure, taking into account an urban planning perspective and capturing the strengths, shortcomings and potentials of Nanchang as a territorial and spatial agglomeration, which can determine, to a great extent, the energetic behaviour of the city and support or discourage a successful integration of energy technologies and systems. This assessment of the spatial characteristics and structural set up of Nanchang was based on information contained in various existing Plans of Nanchang, the Master Plan of the city and numerous local site visits and interviews. Although, empirically challenging due to the limited timeframe, this method of evaluation informed the process of Low Carbon Action Plan development with important conclusions and generated a set of recommendations targeting such transformation of Nanchang, which would introduce more energy efficient and less carbon intense city development patterns.

\subsection{The aggregate key outcomes}

An integration of different methods of analysis revealed numerous shortcomings in the key sectors including industries, energy supply, buildings, transportation and urban structure, all relevant for determining end use energy efficiency, effectiveness of energy supply and related levels of $\mathrm{CO}_{2}$ emissions in the urban context of Nanchang.

The most significant features, prevailing in each sector can be summarized as follows:

- Urban structure: most dominant property of the urban structure in Nanchang is exposed in form of its mono-central character. In addition, a significant level of fragmentation and sprawl, particularly typical in the newly built, mono-functional developments have shown an extensive presence, affecting the $\mathrm{CO}_{2}$ emissions based not only on changes in land use activities but also on lack of conservation of land as a resource. Such patterns of development have far reaching consequences, inhibiting an efficient and concentrated provision of energy infrastructure [12-13], 


\section{$2^{\text {nd }}$ European Energy Conference}

- Buildings: the most prominent deficits found in building sector are characterized by poor quality building envelopes, lack of appropriate definition of energy efficiency standards, an absence of a training and monitoring system enabling implementation of higher building standards. Lack of structures for community energy management form another essential present disadvantage in this context,

- Industries: high energy intensity of industrial sector in Nanchang is predominantly maintained by two industrial branches: steel and paper industries, which contain a large capacity for improvement of efficiency in their production processes,

- Energy: the analysis of present set up of energy supply system in Nanchang has shown that only 1,1 percent of supplied electricity is currently generated using renewable sources,

- Transportation: the present public transport infrastructure consists predominantly of an extensive bus network; its efficiency however, is impaired to a large degree due to frequently appearing traffic congestions in the old city centre of Nanchang and aggravated by the absence of designated bus lines.

\section{The building blocks of an integrated Low Carbon Action plan for Nanchang}

\subsection{Low Carbon City Measures}

Targeting the implementation of low carbon development aims defined in the 12th Five Year Plan of Nanchang [9-10] on the one hand, and taking key findings of the status quo evaluation as the starting point on the other, AIT team of experts has developed a set of 64 Low Carbon City Measures, considered compatible with local conditions of Nanchang. The proposed measures have been clustered by sectors and grouped in technological and non-technological categories; all of them addressing at least one of the following targets:

- Setting up of a renewable portfolio standard for energy supply

- Increasing end use energy efficiency

- Controlling the growth of energy demand

- Reducing consumption of non-renewable resources, including land

- Improving the efficiency and capacity of energy supply network

- Increasing the efficiency of industrial processes and improving energy management system

- Improving the quality and efficiency of transport infrastructure [13]

Proposed set of Low Carbon City Measures address the entire urban energy system and aspire to achieve a more efficient allocation and management of resources.

\subsection{Integrated Low Carbon City Action Plan}

To reach a desirable level of integration of Low Carbon City Measures in concrete, implementable steps of low carbon development activities, an integrated Low Carbon City Action Plan has been set up and discussed during second a joint workshop between Austrian and Chinese experts in Nanchang. This process required a careful weighing and prioritization of specific measures in each sector and their distribution along a time line, focusing on actions to be implemented in the time period 2012 to 2015 and grouping consecutive actions to follow after 2015 [Fig. 2]. The advantages of the Low Carbon City Action Plan defined for Nanchang are threefold. Firstly, it provides decision makers and the local experts with a clearly defined structure for desired interventions, secondly, it can be used for monitoring of implementation of actions and thirdly, it maintains the flexibility to absorb adjustments and changes, if necessary [14]. One of the most profound impacts of the Nanchang Low Carbon Action Plan can be expected in its capacity to initiate a gradual shift from multiple isolated solutions, which address individual technologies and sectors, attempting to decrease the levels GHG emissions and to increase energy efficiency of Nanchang, to a more integrated approach, tying key low carbon activities together and thus increasing their effectiveness. 


\section{Integration of Low Carbon City Measures in the Action Plan}

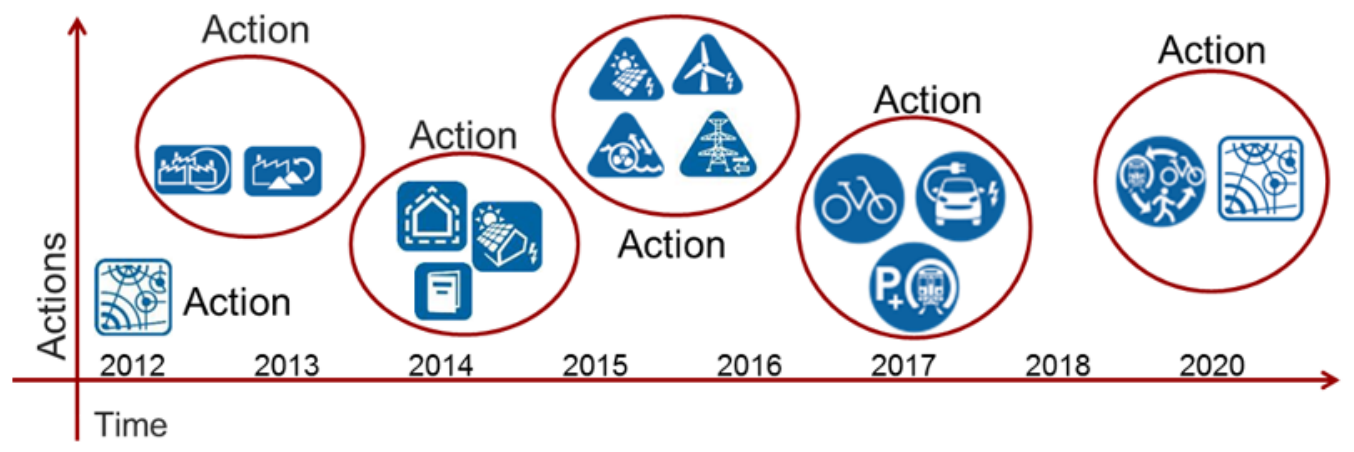

Fig. 2 A Scheme, representing a visualization of the integrated low carbon action plan for Nanchang

\section{Conclusions}

Presented with a Low Carbon City Action Plan, the decision makers in Nanchang have been equipped with a structure, which can be used to initiate profound and constructive changes, bringing desired transformation closer to concrete implemenation. However, the prerequisite for a successful demonstration of pioneering low carbon projects, testing alternative forms of development, is the willingness of all relevant stakeholders to re-define their priorities. Here, the question arises, how far all governmental levels of China are prepared to set up regulatory instruments, to ensure that supportive framework conditions are created and the development outcomes monitored. It remains to be seen to what extent the proposed integrated Low Carbon City Action Plan will become a part of an improved reality in Nanchang.

\section{References}

[1] F. Wu, J. Xu, A. Gar-On Yeh, Urban Development in Post-Reform China. State, market, and space, Routledge, London and New York, 25 (2007)

[2] People's Daily Online, April 15, 2009

[3] N.T. Aden, N. Zheng, D.G. Fridley, How can China Lighten Up? Urbanization, Industrialization, and Energy Demand Scenarios, Ernest Orlando Lawrence Berkeley National Laboratory, 28 ( July, 2009)

[4] B. Skaali, T. Knezevic (Ed.), Chinas Energy Efficiency and Carbon Emissions Outlook. China in the $21^{\text {st }}$ Century, Nova Science Publishers, Inc., New York, 5-13 (2012)

[5] N. Zhou, D. Fridley, M. McNeil, N. Zheng, J. Ke and M. Levine, China's Energy and Carbon Emissions Outlook to 2050, Ernest Orlando Lawrence Berkeley National Laboratory, xi (April, 2011)

[6] You-tien Hsing, The Great Urban Transformation. Politics of Land and Property in China, Oxford University Press, New York, 5-14 (2010)

[7] J. Lewis, Pew Center on Global Climate Change, 1 (March 2011)

[8] Nanchang Statistical Yearbook 2010, China Statistics Press, 26 (2010)

[9] Nanchang Municipal Government, The Implementation Scheme of the National Low-Carbon City Pilot Program for Nanchang, Draft, Translation from Chinese language (2010)

[10] Nanchang Development and Reform Commission, Nanchang $12^{\text {th }} 5$ Year Plan, translation from Chinese language (2011) 


$$
2^{\text {nd }} \text { European Energy Conference }
$$

[11] Emerging Trends in China, Implications and Opportunities for Canadian Business, Department of Foreign Affairs and International Trade, Canada, 15, 22 (2010)

[12] D. Jakutyte-Walangitang, D. Österreicher, J. Page, D. Basciotti and G. Fontanella, Nanchang Status Quo Analysis Report, Austrian Institute of Technology (August, 2011)

[13] D. Österreicher, D. Jakutyte-Walangitang, J. Page, O. Pol, D. Basciotti, G. Fontanella, R. Kitzenberger, H. Brunner and G. Siegel (Austrian Institute of Technology), A. Freudenschuß, P. Weiss (Environment Agency Austria), Nanchang Low Carbon City Measures \& Preliminary Feasibility Report (December, 2011)

[14] D. Österreicher, D. Jakutyte-Walangitang, J. Page, O. Pol, D. Basciotti, G. Fontanella, R. and G. Siegel, Nanchang Low Carbon Action Plan (December, 2011) 